\title{
PROSPECTS FOR GAS SUPPLY AND DEMAND AND THEIR IMPLICATIONS WITH SPECIAL REFERENCE TO THE UK
}

\author{
ALEXANDER G. KEMP \\ LINDA STEPHEN \\ University of Aberdeen
}

Over the next 20 years the gap between gas consumption and production in Western Europe will grow very substantially. Rising consumption and the need for further imports have implications for the provision of adequate infrastructure and the contractual relationships between producers of incremental gas and European buyers. The required investment in both of these activities is taking place in an environment of market liberalization where the pace and extent of regulatory change is difficult to predict. The increased risks and continuous regulatory change make infrastructure-investment decision-making more difficult. As yet, there is no widespread agreement on the most appropriate incentive mechanism. The gas market risks and the higher costs of developing gas fields in frontier areas will have to be reflected in the characteristics of the contracts between producers and buyers. Price-indexation clauses fully reflecting the evolving market conditions will be required.

\section{INTRODUCTION}

Gas demand in Western Europe has been growing rapidly over many years. The European Commission (EC, 2000, p. 49) calculates that in the period 1990-2000 it has grown by 52 per cent for member countries. This rate of growth is much faster than for other main fuels. In the same period nuclear power consumption grew by 23 per cent and oil by only 10 per cent. It is generally agreed that substan- tial growth will continue. The Commission estimates that demand may grow by 19 per cent from 2000 to 2010 , and by 27 per cent to 2015 . Gas is already the second most important fuel in the EU, accounting for over 23 per cent of total primary energy consumption in 2000. On the Commission's forecasts its share could reach 26 per cent in 2010 and 27 per cent in 2015. The absolute amounts are 40 billion cubic feet per day (bncf/day) in 2000, rising to 47 billion in 2010,50 billionin 2015, and51 billionin 2020 . 
The high prospective growth in consumption is confirmed by other studies. The International Energy Agency (2000), estimates that primary gas demand for all OECD Europe could increase from $40 \mathrm{bncf} /$ day in 1997 to 61 billion in 2010 , and 77 billion in 2020 , an annual average increase of 2.8 per cent over the whole period.

There are several energy policy implications of these prospective consumption trends. The source of the required gas is an obvious one. Equally important is the infrastructure network of the necessary capacity and in the appropriate location to ensure that the needs of consumers are efficiently met. This paper provides a detailed analysis of the nature and scale of the issues as they are likely to emerge in the UK, and also examines the policy issues for the EU as a whole.

\section{UK GAS MARKET-BACKGROUND}

The UK gas market has undergone some fundamental changes in the last few years. The emergence of a substantial excess of producing capacity above UK demand in early 1995 led to a dramatic fall in beach prices. The gas bubble continued until after the Interconnector between Bacton and Zeebrugge opened in late 1998. This coincided with a period of low oil prices, and the full implications of the link with the Continent were not appreciated until some time later when the oil price recovered. Wholesale gas prices on the Continent in the longterm contracts with Norway and Russia are largely indexed to oil prices. The sustained increase in oil prices thus led to major gas price increases in 2000. In turn this led to substantial exports from the UK through the Interconnector and a dramatic increase in UK wholesale prices.

In recent years UK internal gas consumption has grown substantially, fanned in particular by sharply increasing demand from the power generation sector. Uncertainty regarding market prospects was increased as a result of the moratorium on the use of gas for power generation, its subsequent removal, and the introduction of coal subsidies. On the supply side the UK Continental Shelf (UKCS) is now a mature province, characterized by declining production from older fields and generally smaller sizes of new fields. The Southern North Sea is particu- larly mature. New discoveries tend to be small, though the exploration success rate has kept up surprisingly well. A growing proportion of total production now comes from central and northern waters. Substantial new field developments have recently been completed in the Central North Sea in particular. In these fields gas is generally found in association with oil or condensate. A consequence of this joint product feature is a reduction in the swing factor relating to gas sales contracts compared to the position in the Southern North Sea, where dry gas dominates. Since the opening of the Interconnector, exports in the summer months have increased substantially, reducing the importance of the seasonality of UK market demand to gas producers.

\section{POTENTIAL UK GAS PRODUCTION}

\section{(i) Data and Methodology}

Future UK gas production depends on a number of factors such as oil and gas prices, the exploration effort and success rate, field sizes, and development and operating costs. To reflect the sensitivities, three price assumptions are employed. In the medium case the oil price is $\$ 20 / \mathrm{barrel}(\mathrm{bbl})$ and the gas price $18 \mathrm{p} /$ therm for new contracts, both in constant real terms. In the low case the prices are $\$ 12 / \mathrm{bbl}$ and $12 \mathrm{p} /$ therm, and in the high case $\$ 28 / \mathrm{bbl}$ and $25 \mathrm{p} /$ therm.

The study was conducted with the aid of a large field database. The first element contains key information on 247 sanctioned fields relating to production, and development, operating, and decommissioning costs. The second element contains similar information on 97 (unsanctioned) incremental projects associated with these fields. The third element contains similar information on 65 'probable' fields and 56 'possible' fields. In all three cases the data have been supplied by the operators. A fourth database contains very summary information on 234 other fields, known as 'technical reserves'.

The Monte Carlo technique was employed to estimate likely future gas discoveries. The modelling involved several steps. Historic success rates for each of the main regions of the UKCS were found from DTI $(2001 a)$. In line with experience in the 
Table 1

Significant Exploration Success Rates (\%): Medium Case

\begin{tabular}{lrrrr}
\hline & 2001 & 2005 & 2010 & 2015 \\
\hline Central North Sea & 16.1 & 15.3 & 14.3 & 13.3 \\
Northern North Sea & 21.1 & 20.3 & 19.3 & 18.3 \\
West of Scotland & 8.3 & 7.5 & 6.5 & 5.5 \\
Irish Sea & 17.8 & 17.0 & 16.0 & 15.0 \\
Southern North Sea & 25.5 & 24.7 & 23.7 & 22.7 \\
\hline
\end{tabular}

Table 2

Number of Exploration Wells: Whole UKCS

\begin{tabular}{lrrrr}
\hline & 2000 & 2005 & 2010 & 2015 \\
\hline Medium case & 30 & 25 & 20 & 18 \\
Low case & 10 & 8 & 6 & 5 \\
High case & 50 & 40 & 30 & 25 \\
\hline
\end{tabular}

Table 3

UKCS Mean Discovery Size (mmboe) ${ }^{\mathrm{a}}$

\begin{tabular}{lrrrr}
\hline & 2000 & 2005 & 2010 & 2015 \\
\hline Central North Sea & 32 & 28 & 24 & 20 \\
Northern North Sea & 16 & 14 & 12 & 10 \\
West of Scotland & 200 & 175 & 150 & 125 \\
Irish Sea & 42 & 37 & 32 & 26 \\
Southern North Sea & 21 & 18 & 16 & 13 \\
\hline
\end{tabular}

Note: ${ }^{\text {a }}$ Million barrels of oil equivalent.

1990s it was assumed that the success rate will decline slowly over time. Details for the medium case are shown in Table 1.

For the high case the success rates are assumed to be 5 per cent higher and for the low case 5 per cent lower than the medium case. For each of the UKCS basins the relative chances of finding oil, gas, or gas/condensate were based on experience in the 1990s.

The exploration effort is a function of a number of factors including prospectivity, oil and gas prices, and net cash flows from ongoing activities. Distinguishing among them is complex, and for present purposes it was felt appropriate to consider three cases. In the medium case there are 30 exploration wells in 2000 , falling to 18 by 2015 for the whole of the UKCS. Table 2 shows the numbers in the three cases.

From data relating to the 1990 s the exploration effort in each region was calculated. This was used to distribute the exploration wells among the five regions.

The average size of discovery in the UKCS has been declining for some time. The average size of future discoveries in each of the UKCS regions is based on historic trends in the 1990s. The numbers are shown in Table 3.

To undertake the full financial modelling of new discoveries, information is also required on their likely development and operating costs. Examination of the development costs of the 'probable' and 
'possible' fields given by the operators provided useful information to estimate the likely costs of developing new discoveries. The average development cost in the Southern North Sea was taken to be $\$ 3$ per barrel of oil equivalent (boe), for West of Scotland $\$ 5$, and for the rest of the UKCS $\$ 4$.

The next step in the modelling process involved the design of distributions of field size and development costs. In line with experience to date, the field size distributions were assumed to be lognormal. A standard deviation of 50 per cent of the mean value was used. The development cost distributions were assumed to be normal with a standard deviation of 20 per cent of the mean value. The annual operating costs were set at 5-15 per cent of accumulated development cost depending on the field size found. This again reflects historic experience. These costs are relatively lower on large fields, reflecting the economy of scale.

Using the above assumptions on exploration effort, exploration success rates, and the distributions of field sizes and development costs, the Monte Carlo technique was employed to produce a database of discovered fields found through time for the medium, low, and high cases. Simulations were conducted separately for each of the five regions.

It was assumed that there would be a 2-year time lag between discovery and the start of development in the Southern North Sea. For the rest of the UKCS the time lag was assumed to be 4 years.

From the sanctioned, 'probable', and 'possible' fields, and the new discoveries from exploration, a profile of potential field developments over time was produced. The 'technical reserves' were then added with constraints to the 'possible' fields. The constraints took the form of a ceiling on the total number of potential developments in each year. These were based on experience in the 1990s. For the medium case the ceiling was 15 new field developments per year, for the low case 12 , and for the high case 20 new developments per year. If the number of new developments from the 'probable', 'possible', and new discovery categories was less than the ceiling, the Monte Carlo technique was used to sample from the bank of 'technical reserves', and the chosen fields were added to the 'possible' category. The development costs for these additional 'possible' fields were drawn from distributions with mean values $\$ 2 /$ boe higher than those assumed for new discoveries. The standard deviations were again set at 20 per cent of the mean values.

All new fields and the incremental projects were subjected to economic testing. Using real discount rates of 10 per cent and 15 per cent post-tax net present values were calculated. If the results were positive the field development was triggered. The 10 per cent rate is generally employed in the results presented below. Where the 15 per cent rate makes a significant difference, attention is drawn to the effects. In the results the medium case reflects the effects of the combinations of medium price, exploration effort, and success rates. The high and low cases reflect corresponding combinations. The three elements of each case are not presumed to be causally linked.

\section{(ii) Results}

\section{By field category}

The results of the modelling can be shown to emphasize different features. One way is by category of field. This enables deductions to be made regarding the probabilities of different outcomes.

Figure 1 shows potential gas production under the medium case. In 2001 the total is 11,465 million cubic feet per day (mmcf/day), in 200512,942 $\mathrm{mmcf} /$ day, in $20107,112 \mathrm{mmcf} /$ day, and in 2015 $4,299 \mathrm{mmcf} /$ day. Production from the sanctioned fields peaks at $11,784 \mathrm{mmcf} /$ day in 2002 , then declines quite rapidly to $3,622 \mathrm{mmcf} /$ day by 2010 . In 2004 the incremental projects contribute more than $1,123 \mathrm{mmcf} /$ day to the production of this category of field. By 2010 they contribute only 372 mmcf/day.

Production from the 'probable' fields rises quickly to peak in 2005 at 2,739 mmcf/day, and declines to $1,173 \mathrm{mmcf} /$ day by 2010 . Output from the 'possible' fields grows more slowly to peak in 2008 at 1,653 $\mathrm{mmcf} /$ day and is $1,600 \mathrm{mmcf} /$ day in 2010 . With a 15 per cent cost of capital, production from this category is lower throughout with a peak in 2006 at $1,560 \mathrm{mmcf} /$ day. Output from new discoveries 
Figure 1

Potential Gas Production: Medium Case (cost of capital 10\%)

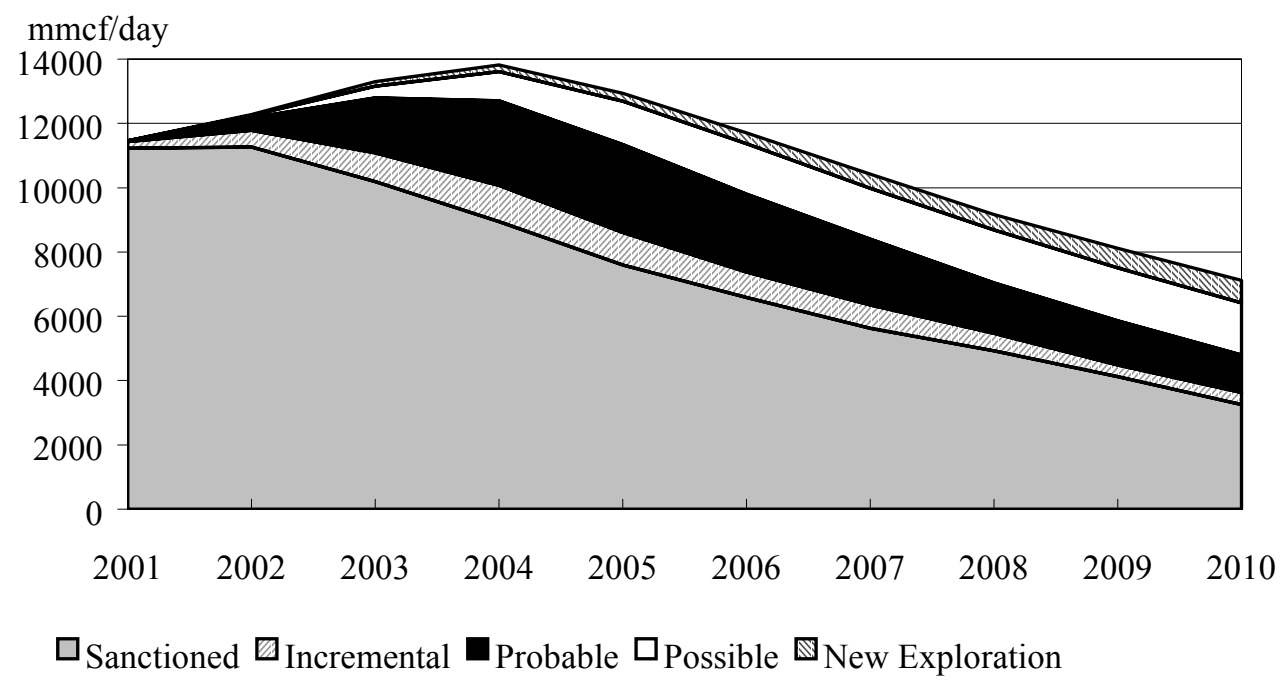

grows much more slowly to reach $695 \mathrm{mmcf} /$ day by 2010 and $796 \mathrm{mmcf} /$ day by 2015 .

Production from the sanctioned fields clearly has the highest probability of being achieved. There may be more incremental projects in the medium term which could further enhance production from this category of field. Significantly greater uncertainty is attached to output from the 'possible' fields and new discoveries. It is noteworthy that in 2010 production from the sanctioned fields still accounts for 51 per cent of total output. By 2015 the share is as high as 34 per cent.

Under the low case, production is not markedly different in the short term because sanctioned fields dominate the total, but in the longer term the difference becomes more marked, as fewer new fields are developed and fewer discoveries made. In 2005 total output is around 96 per cent of that under the medium case. By 2010 it is 83 per cent and by 2015 58 per cent. Production from the sanctioned fields is even more important under this scenario. By 2010 output from this category still accounts for 62 per cent of the total, and by 201556 per cent.

There is not a major difference in output from the sanctioned fields under the two scenarios. A main reason for this is the importance in the total output of relatively 'old' gas contracts, where the influence of spot prices and/or those for new contracts is less.
In the longer term the main sources of the substantially lower output under the low case emanate principally from fewer new discoveries and a lower number of field developments in the 'possible' category. Production from new discoveries under this scenario is small, being 11 per cent of that under the medium case in 2010, and 23 per cent in 2015.

Under the high case, production in the short term is also not markedly different from the medium case because of the predominance of the sanctioned fields in the total. In the longer term the differences become greater. In relation to the medium case total output becomes 103 per cent in 2005, 111 per cent in 2010 , and 119 per cent in 2015 . These findings indicate that from the base of the medium case, the long-term responsiveness of output is considerably greater to the parameter values in the low case compared to those of the high case.

Consistent with the above, under the high case production from new discoveries in 2010 is double that in the medium case. In 2015 it is 163 per cent higher. Output from the 'possible' fields is 110 per cent of that under the medium case in 2010.

The results for the three scenarios indicate the sensitivities of long-term gas production to plausible variations in the factors determining activity levels. Some increase can confidently be predicted over the next few years, after which the rate of produc- 
Figure 2

Potential Gas Production: Medium Case (cost of capital 10\%)

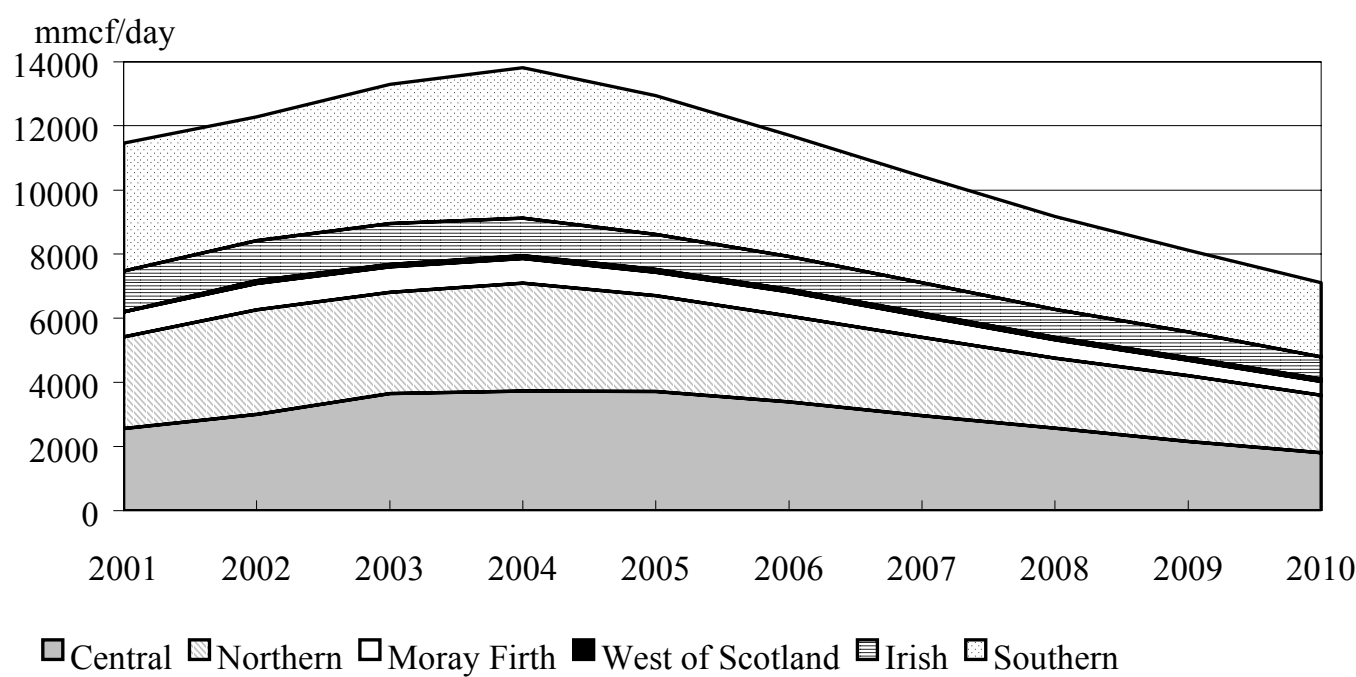

tion decrease depends on a variety of factors. One implication of the findings is the importance of the maintenance of a substantial exploration effort. Exploration has fallen markedly in recent years, and has only slowly recovered despite the large increase in oil and gas prices.

\section{By producing area}

It is also useful to examine gas production by geographic area, as this has significant implications for infrastructure provision. Figure 2 shows potential production from each of the UKCS areas under the medium case. Production from the Southern North Sea peaks in 2004 at 4,706 mmcf/day, then declines to $2,321 \mathrm{mmcf} /$ day by $2010(2,108 \mathrm{mmcf} /$ day with 15 per cent cost of capital). By 2015 it becomes $1,680 \mathrm{mmcf} /$ day $(1,562 \mathrm{mmcf} /$ day with 15 per cent cost of capital). It is noteworthy that the share of the Southern North Sea in total production holds up very well to 2015, despite the greater maturity of this basin and the fact that its share has decreased over the last decade. In 2004 it accounts for 34 per cent of the total, in 201033 per cent, and in 201539 per cent.

The Central North Sea has seen a large growth in output over the last decade. The results indicate that production (excluding the Moray Firth) will increase in the next few years, peaking in 2004 at 3,725 $\mathrm{mmcf} /$ day (27 per cent of the total), and then decline to $1,805 \mathrm{mmcf} /$ day in 2010 ( 25 per cent of the total), and $909 \mathrm{mmcf} /$ day in 2015 (21 per cent of the total). Output from the Moray Firth area peaks in 2002 and by 2010 becomes quite small. Production from the Northern North Sea will follow a path similar to that for the Central area. The volumes to 2010 are very similar. Production from the three areas is most likely to land at St Fergus, with implications for the provision of infrastructure. The findings in this study are that the combined production could peak in 2004 at $7,903 \mathrm{mmcf} /$ day. By 2010 it could be $4,025 \mathrm{mmcf} /$ day.

The results of the modelling indicate that production from West of Scotland is quite small throughout the period. This reflects the generally low levels of exploration success historically. Because large areas are as yet unexplored it is possible that substantial discoveries will be made, but the risks involved are high.

Production from the Irish Sea is estimated at 1,271 $\mathrm{mmcf} /$ day for 2001 . It falls gently to $689 \mathrm{mmcf} /$ day by 2010 .

Under the low case, production is less in each area compared to the medium case, but there are significant variations across regions. These become pronounced in the longer term when the effects of reduced exploration and new field developments 
become more noticeable. Thus, in the Southern North Sea output in 2010 at 1,660 mmcf/day is 655 $\mathrm{mmcf} /$ day less than in the medium case. The result is that this area accounts for 28 per cent of total production in that year, compared to 33 per cent in the medium case.

In relative terms production is not reduced so much in the other areas under the low case. In the Central North Sea (excluding Moray Firth) it becomes 1,511 $\mathrm{mmcf} /$ day in 2010, accounting for 26 per cent of the total. The share of the Northern North Sea increases over the period to account for 28 per cent of the total in 2010. In that year the aggregate output from Central North Sea, Moray Firth, and Northern North Sea is $3,214 \mathrm{mmcf} /$ day or nearly 55 per cent of the total.

There are several noteworthy implications of the results. The Southern North Sea fields contain dry gas, and so contracts with substantial swing factors can be made. In Central and Northern waters the gas is usually associated with oil or condensate and large swing factors cannot readily be accommodated in contracts consistent with profitmaximization from the production of liquids. (This point can, however, be overemphasized, because maintenance work involving the shut-down of production facilities is generally concentrated in the summer months when gas demand is seasonally low.) The substantial sensitivity of the relative contribution of the Southern North Sea to the parameter values is of some importance given the high seasonal variation in UK gas demand.

Under the high case, while production in each of the areas is greater than under the medium case, the differences vary in the longer term. Output from the Southern North Sea is particularly responsive. By 2010 it is $461 \mathrm{mmcf} /$ day higher than under the medium case and accounts for 35 per cent of total production. In 2015 the share from this region increases to over 40 per cent.

Production from the Central North Sea increases to a modest extent while that from the Northern North Sea increases by only a minor amount. The result is that in 2010 combined production for Central North Sea, Moray Firth, and Northern North Sea is 4,123 $\mathrm{mmcf} /$ day or 52 per cent of the total.

\section{SIZE AND LOCATION OF UK PRODUCTION AND RELATED NTS CAPACITY}

The geographic location of future production is of interest because the infrastructure of the necessary size has to be available to receive the gas. Such infrastructure relates to terminal facilities and the National Transmission System (NTS). In recent years there has been some debate about the adequacy of the NTS capacity at certain points, notably St Fergus. The projections obtained in this study have been used to assess the extent of this problem. The destination by terminal of production from sanctioned fields (including incremental projects) is already known. The likely destinations by terminal of production from the 'probable' and 'possible' fields (including 'technical reserves') can be estimated with a reasonable degree of assurance, given the knowledge regarding the location of the fields and the offshore infrastructure. Production from new discoveries has not been included in this part of the study because of inadequate knowledge of their precise location. This probably does not affect the validity of any findings regarding the adequacy of the system because significant production from new discoveries will not occur until after total UK output has passed its peak. It is emphasized that the production figures are on an average annual basis.

Transco has made several estimates of NTS capacity at the different terminals. In Transco (2000) estimates are provided of the system entry point maximum unconstrained physical capacities for 2000/1. In Transco (2001 $a, b)$ various estimates are provided of the peak day planned entry capacity based on the 1-in-20 winters licence obligation. Two cases are given. One is termed 'St Fergus Base' case. The second is 'St Fergus Expansion' case.

The projections of potential production arriving at the various terminals are now examined against the possible NTS capacities. In Figure 3 the position at St Fergus is shown. The production projections reflect the medium case. The unconstrained capacity as indicated in Transco (2000) is only slightly above the expected average production figure for 2001 and equal to it for 2002. There is no difference between the two cases until the later years of the 
Figure 3

UK Production and Capacity at St Fergus: Medium Case

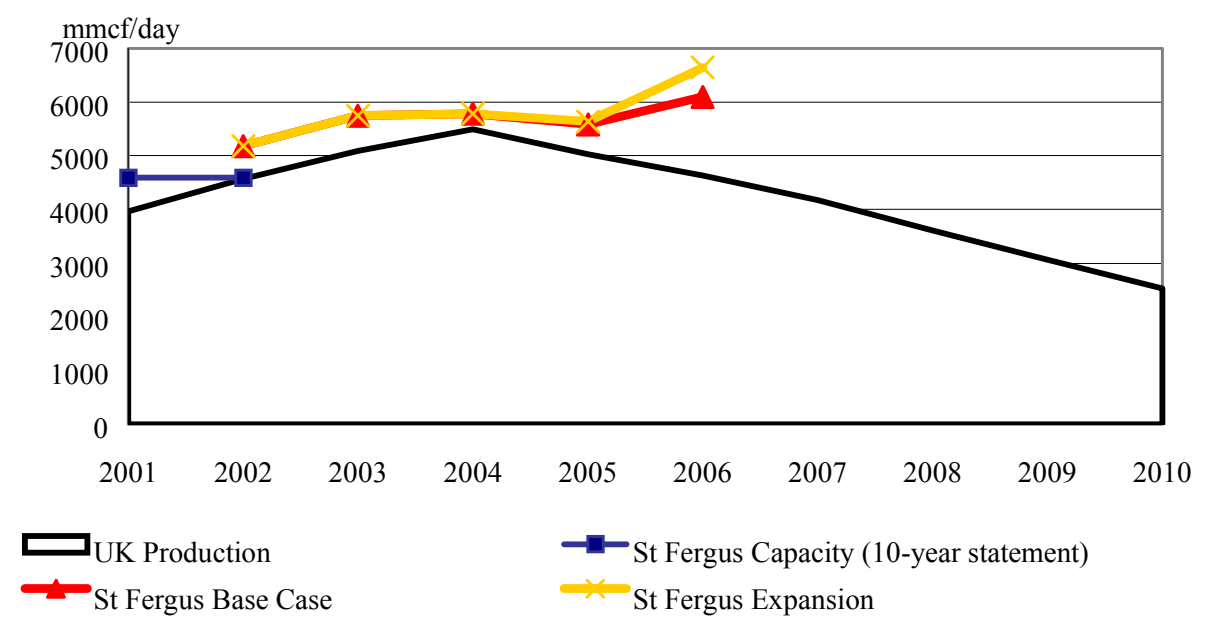

forecast period. Up to and including 2004, capacity just exceeds production. When the recent BP contract involving imports from Norway of $163 \mathrm{mmcf} /$ day for 15 years starting in late 2001 is added, there is very little spare capacity. When the peak winter situation is considered, the position is still tighter. In January 2001, 4,342 $\mathrm{mmcf} /$ day of gas landed at the terminal. Further imports may be expected. There will almost certainly be further significant UK production from new discoveries hoping to land at $\mathrm{St}$ Fergus. On the other hand, some production landed at St Fergus is diverted away from the NTS to Peterhead power station. This has a capacity of around 1,500 MW. It should be noted that no steps have yet been made to install capacity above the base case.

In Figure 4 the position at Teesside is shown. In this case the maximum unconstrained capacity as reported in Transco (2000) just exceeds the average production in 2002. Throughout the period the capacity indicated in Transco (2001b) is below the anticipated production. It should be noted that at Teesside there are substantial gas deliveries outside the NTS, mostly for power generation. These have recently been in the range $400-800 \mathrm{mmcf} /$ day. This removes the apparent deficit. On the other hand, there will probably be further production destined for Teesside from new discoveries in the Central North Sea and possibly imports from Norway in the longer term.

In Figure 5 the position at Barrow is shown. It is seen that under all cases there is generally a surplus of capacity at the NTS above prospective average annual production landing at Barrow. In this case the difference between average annual and peak winter production is very large, because the Morecambe field has a large swing factor to meet winter demand. Thus in January 2001, production of 1,768 mmcf/day landed at Barrow.

In Figure 6 the position at Theddlethorpe is shown. From Transco (2000) it is seen that the maximum unconstrained physical capacity exceeds the likely production arriving at Theddlethorpe. The Transco (2001b) scenarios indicate a deficit of capacity, particularly in the later years with the St Fergus expansion case. It should be noted, however, that some gas which is landed at Theddlethorpe bypasses the NTS, including in recent years around $350 \mathrm{mmcf} /$ day destined for power generation. When this is taken into account the problem is not so noticeable.

In Figure 7 the position is shown at Easington/ Dimlington. Capacity is far above prospective production levels. It is important to note that the capacity has to handle gas from the Rough field which is employed for storage to meet peak demand requirement. The gas deliverability from this field is as much as $1,543 \mathrm{mmcf} /$ day. When this is added to production the total capacity requirement in 2004 exceeds $2,500 \mathrm{mmcf} / \mathrm{day}$.

In Figure 8 the position at Bacton is shown. This reveals that under both scenarios there is likely to be adequate capacity in the NTS. If the import capacity 
Figure 4

UK Production and Capacity at Teesside: Medium Case

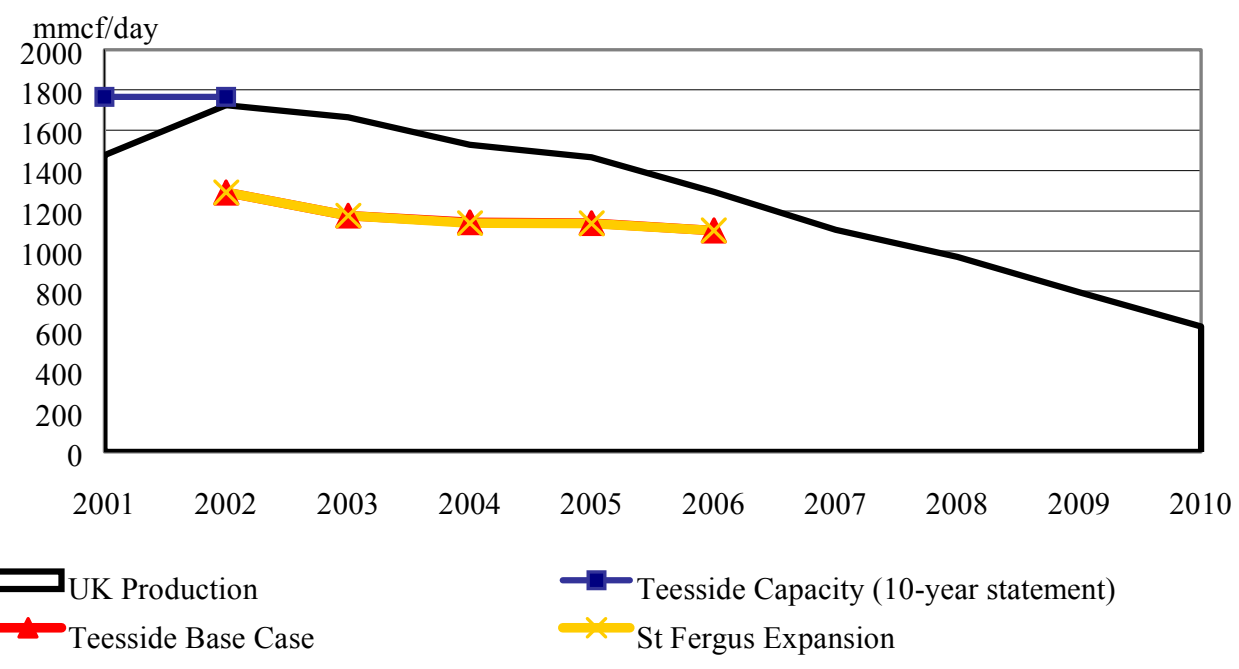

Figure 5

UK Production and Capacity at Barrow: Medium Case

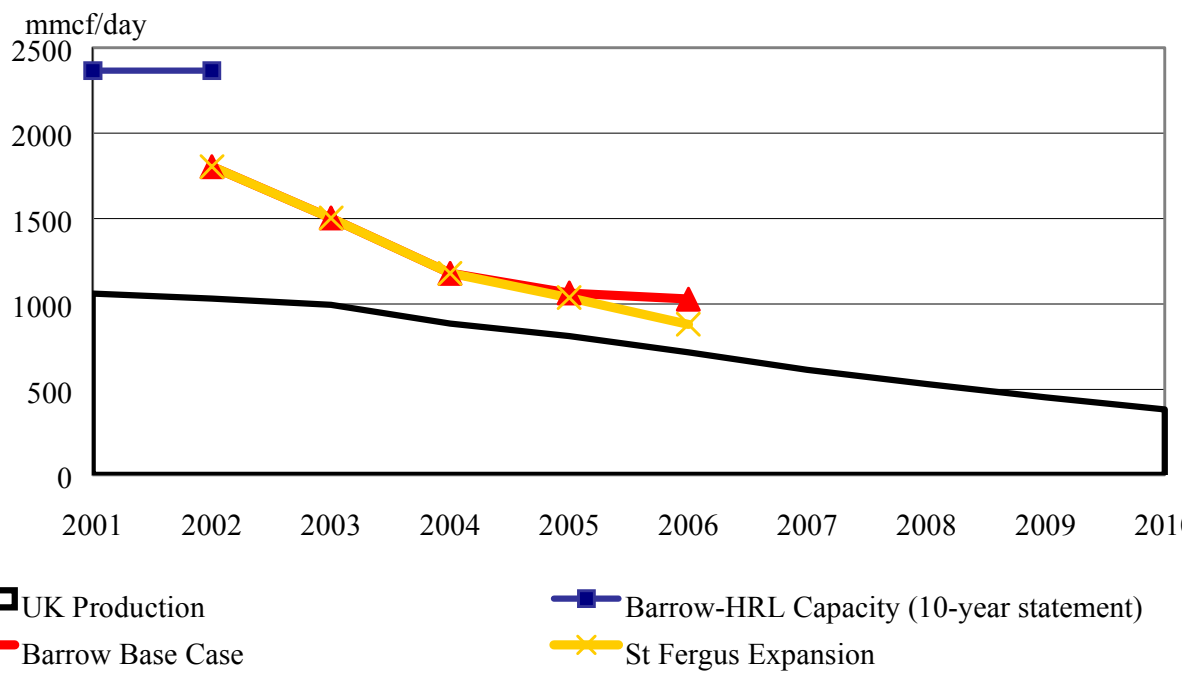

Figure 6

UK Production and Capacity at Theddlethorpe: Medium Case

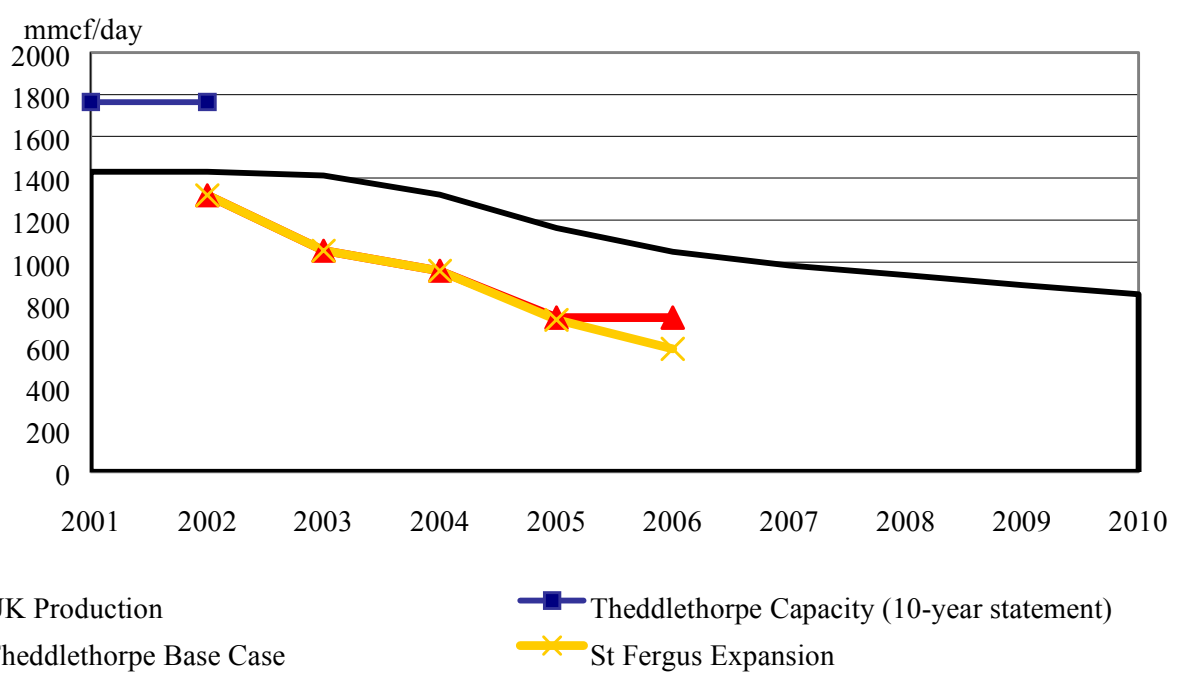


Figure 7

UK Production and Capacity at Easington and Dimlington: Medium Case

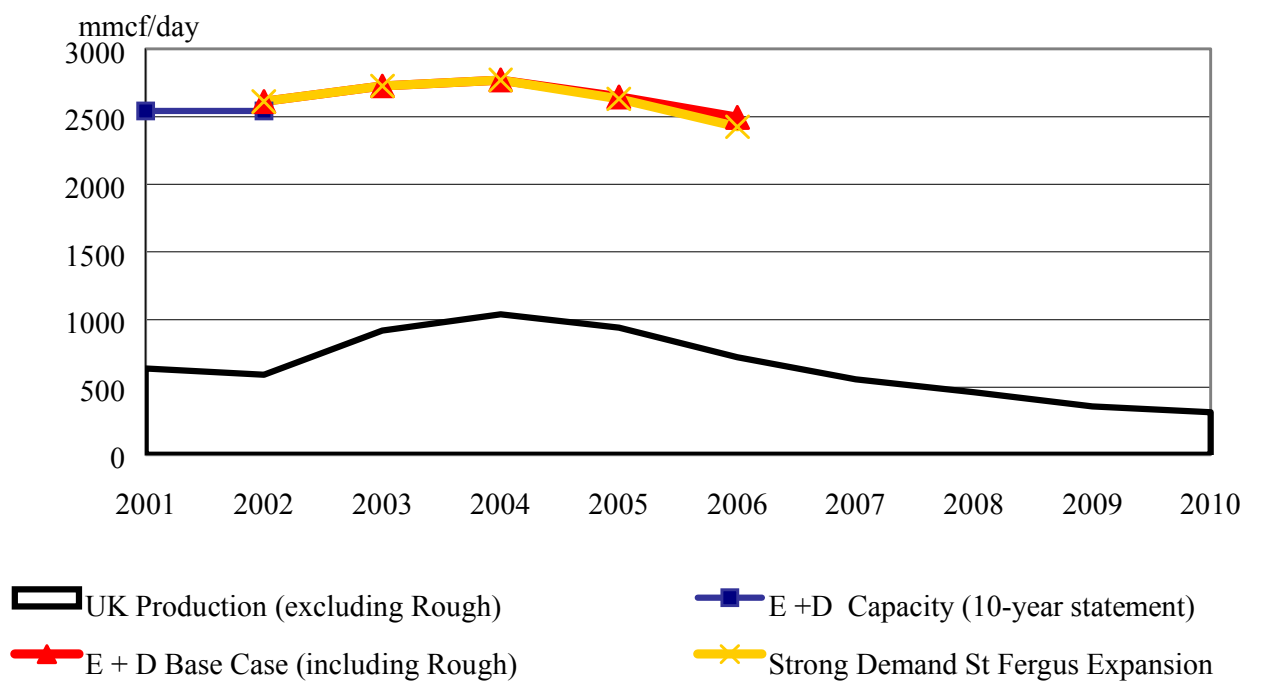

Figure 8

UK Production and Capacity at Bacton: Medium Case

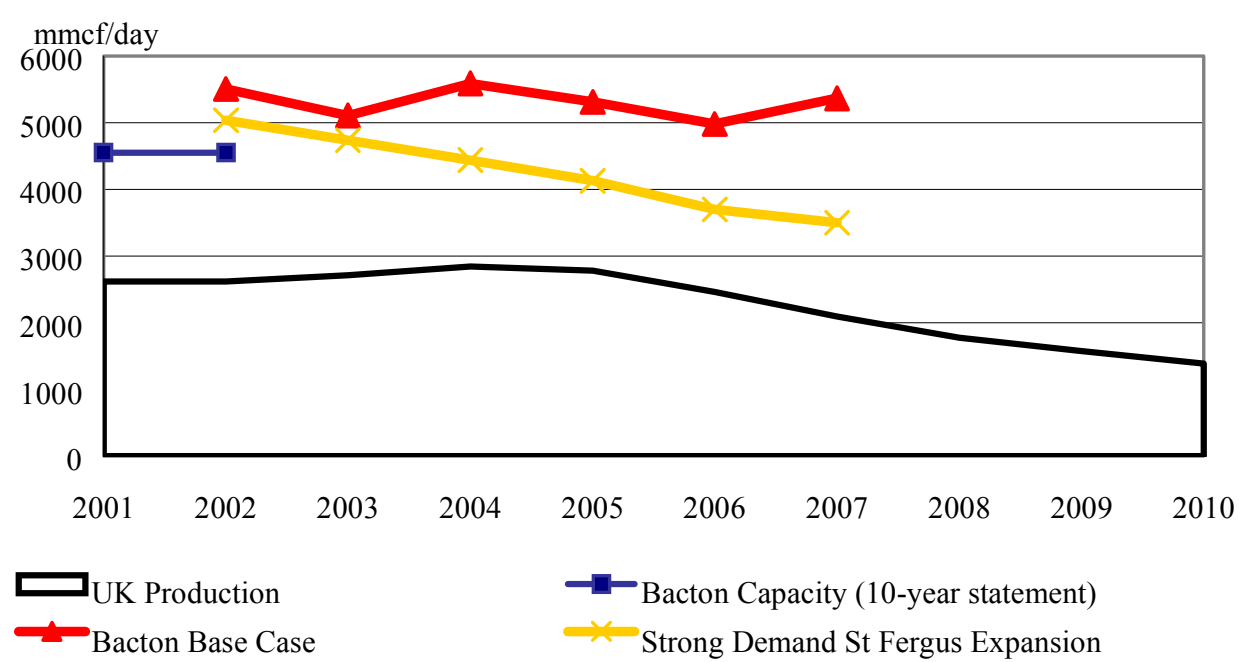

of the Interconnector is eventually expanded to match its current export capability of around 2 billion cubic feet per day, there should still be enough overall capacity.

\section{BALANCE OF UK PRODUCTION AND DEMAND}

In this section estimates of UK demand are set alongside prospective UK production. Several recently published projections are used, namely DTI (2001b), Transco (2000, 2001a), and the Energy Contract Company (ECC, 2001).
The DTI projections are based on a large econometric energy demand model involving the disaggregation of final user demand into several sectors. Allowance is made for changes in energy efficiency. The effect of the Climate Change Levy (CCL) on demand in the business sector is incorporated. Six core scenarios are developed, incorporating various combinations of GDP growth rates and energy prices. The high-gas-price scenario has delivered prices (expressed in 1999 values) rising to reach in 2010 (a) 24.3 pence per therm in the industrial sector, (b) 28.5 pence to the services sector, and (c) 62 pence in the domestic sector. Under the low-price case the corresponding values 
Figure 9

Potential UK Gas Production and UK Demand: Medium Case (cost of capital $10 \%$ )

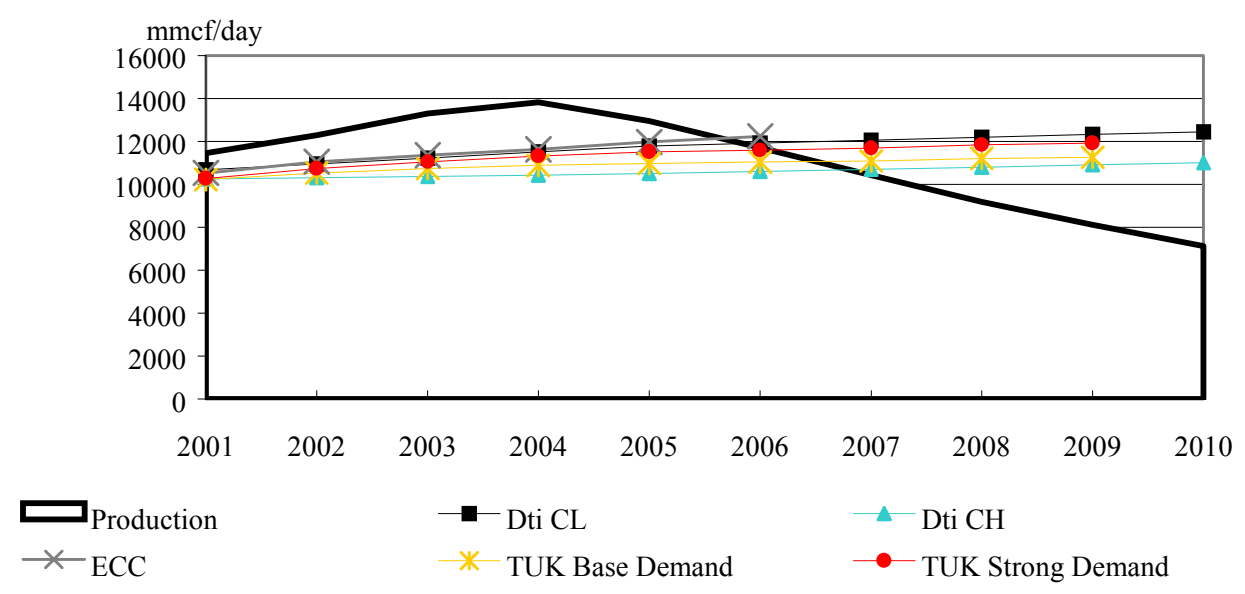

are (a) 12.3 pence, (b) 17.6 pence, and (c) 40.4 pence.

Transco's base case assumes a period of recession in the short term, which causes a decrease in the rate of growth in demand for gas. Increased efficiency in the use of gas is assumed. The introduction of the CCL also has a negative impact on demand growth in the non-domestic sectors. Another assumption involves a further shift from manufacturing to services, which has a negative effect on demand growth. Further assumptions include the greater use of renewables in the combined-heatand-power market and the absence of a further 'dash for gas' in power generation.

Transco's strong demand scenario incorporates relatively fast economic growth in all sectors of the UK economy, while gas remains competitive in price terms. Power generation continues to grow, and the share of gas in power generation increases to 50 per cent.

In Figure 9 the scenario involving the medium case for UK production is shown along with two Department of Trade and Industry (DTI) demand scenarios, namely central GDP growth and low and high gas prices ( $\mathrm{CL}$ and $\mathrm{CH}$ ). The results in Figure 9 indicate that the UK remains self-sufficient on a net basis until 2006, after which the need for imports rises at an increasing rate. By 2010 they are in the range 3.8-4.4 billion cubic feet per day (bncf/day). These correspond to $35-43$ per cent of primary gas demand under the $\mathrm{CH}$ and CL scenarios. By 2015 they could be as much as $7.5-8.8 \mathrm{bncf} /$ day which correspond to 64-68 per cent of primary gas demand. It should be noted that the date of net imports commencing and the scale of the imports depend upon the net surplus of UK production over the next few years being exported. To the extent that the surplus is not exported, the date at which net imports commences is extended beyond 2006.

The balance of UK production in the low case was next compared with the various UK demand estimates. In this case the DTI projections relate to (i) high economic growth and low gas price (HL), (ii) low economic growth and low gas price (LL), and (iii) central economic growth and low gas price (CL). The result was that in most projections net imports are required in 2005 . The surplus of production over UK demand over the next few years is also smaller. By 2010 the required net imports are in the range 3.8-5.3 bncf/day. Under the CL scenario these imports would account for 53 per cent of primary gas demand. In 2015 they would account for 81 per cent of primary demand. In that year they could be a massive 10.5-11 bncf/day.

In the high case the DTI demand scenarios employed are (i) high economic growth and high gas prices (HH), (ii) low economic growth and high gas prices (LH), and (iii) central economic growth and high gas prices $(\mathrm{CH})$. Under most of the demand scenarios, UK net self-sufficiency extends to 2007. The size of the surplus of production in the interven- 


\section{Figure 10 \\ Potential UK Gas Production and Demand Including Exports: Medium Case (cost of capital 10\%)}

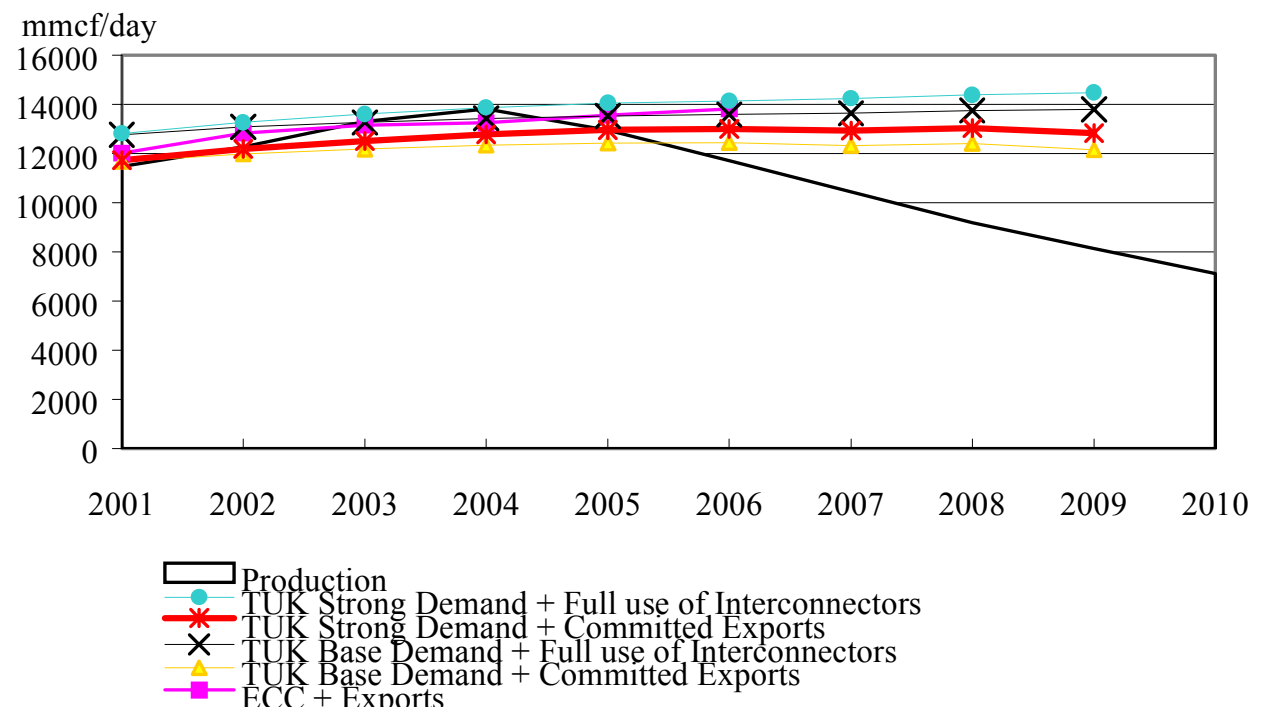

ing years is greater than in the other cases. By 2010 the net import requirements are in the range 2.6-3.3 bncf/day. These correspond to 28-37 per cent of primary gas demand. By 2015 they are in the range 6.3-7 bncf/day. These correspond to 57-62 per cent of primary gas demand.

There are now substantial exports of gas from the UK. The Energy Contract Company (2001) estimates current long-term export contracts through the Bacton-Zeebrugge Interconnector at around $1,080 \mathrm{mmcf} /$ day and exports to Southern Ireland at around $600 \mathrm{mmcf} / \mathrm{day}$. To complete the picture of the balance between UK production and demand, estimates of committed exports were added to UK internal demand. A further case, where full use was made of the Interconnector's export capacity, was also examined.

In Figure 10 the results are shown for the medium case regarding production, along with the Transco and ECC's estimates of UK demand plus exports. Given the current export commitments in 2001, the balance between UK production and demand is fairly tight.

If full use were to be made of the Interconnector for exports, there is no excess producing capacity above the sum of internal demand plus exports. Imports are required in 2001 and in 2002.
Under the low case the scale of the growth in gross imports from 2004 onwards becomes substantially greater, and the size of the surplus of UK producing capacity above UK demand and committed exports over the next few years considerably less than in the medium case.

In the high case with some of the internal demand scenarios the timing of the need for substantial gross imports is extended to 2006 . The market remains relatively tight in 2001 and 2002. With full use of the Interconnector for exports, significant gross imports would be required in 2001 and 2002.

\section{EUROPEAN GAS IMPORT DEPENDENCE}

The results in sections IV and V have highlighted the possible extent of the UK's gas import dependence over the next 15 years and the consequent effect on the need for appropriate infrastructure for Europe. The European Commission (EC, 2000) calculates that in 2000 for member countries 40 per cent of gas requirements were imported. Of these, 41 per cent came from Russia, 25 per cent from Norway, and 29 per cent from Algeria. The Commission estimates that by 2010 imports could account for 52 per cent of demand and by 202066 per cent. In the latter year as much as 38 per cent of total gas requirements 
could come from Russia, 34 per cent from Norway, and 23 per cent from Algeria. The International Energy Agency (IEA, 2000, p. 366) estimates that, for OECD Europe, imports could grow from 31 per cent of total gas requirements to 64 per cent in 2020 .

These are high percentages of large absolute gas requirements (see section I). They clearly indicate the need for further infrastructure provision. They also raise questions regarding security of supply and the nature of the contracts between gas producers and buyers which inevitably involve the arrangements for access to the infrastructure.

\section{INFRASTRUCTURE PROVISION}

In the UK Transco has a responsibility to provide infrastructure, particularly in the form of the NTS and a local distribution network. The regulatory system has been changed frequently over the years. As far as provision of transmission capacity is concerned, recently there has been a debate about the appropriate long-term investment signals and incentives. The existing mechanism for determining the amount of long-term capacity in the NTS is the obligation placed on Transco to meet the peak aggregate demand which is likely to be exceeded only 1 in 20 years taking into account the experience of the last 50 years. The Office of Gas and Electricity Markets (Ofgem) believes that this scheme is not appropriate for a liberalized gas market. In particular, under the present system, if a shipper desired some (extra) capacity at a specified terminal, Transco has no obligation to invest in extra capacity so long as the 1 in 20 national peak day requirement is being met.

Ofgem is also concerned that the present system does not help to promote desired competition among shippers and suppliers. The regulator also believes that the determination of economic and efficient capital expenditure (which has been the subject of disagreement between Ofgem and Transco) can be better determined by other mechanisms.

Ofgem favours the employment of both short-term and long-term auctions of capacity for entry to and exit from the NTS. Short-term auctions are already employed. Ofgem $(2000 a)$ argues that in the short term price auctions provide the most efficient means of allocating the finite capacity. The system is based on willingness to pay and will reveal the true valuations placed on capacity by bidders. It is also argued that the mechanism permits buyers to place different values on capacity through time and at different entry points to the system. This system has been in operation since September 1999 when auctions commenced for 6-month periods. With respect to the longer term, when the amount of capacity can be varied, Ofgem argues that the prices in long-term auctions provide signals to Transco regarding the need to enhance capacity at the different entry points. In Ofgem (2000b) it was emphasized that the auction system would also ensure that there was non-discrimination in the sale of capacity, which would help to ensure that competition in the supply of gas was not distorted. For the longer term, auctions for 5-year periods have been suggested. As with short-term auctions, shippers who require the capacity would make the bids. Trading in a secondary market would be permitted.

The proposals have aroused considerable controversy. Transco, shippers, and producers have all expressed reservations. One area of controversy concerns the accuracy of investment signals provided by the system. It has been suggested by critics (Ofgem, 2000b, 2001) that shippers may well make bids based on short-term and diverse objectives rather than on the need for long-term capacity. Further, they may be unwilling to make long-term commitments to entry capacity faced with $(a)$ one major competitor, and $(b)$ uncertainty regarding future market prospects. Sceptics have also pointed out that the experience to date with short-term contracts has not resulted in a stable, transparent, or simple arrangement. Because there is a revenue cap under Transco's price control formula, a rebate to shippers is required if the auctions resulted in over-recovery of revenues by Transco. It has been argued that this could result in distorting bidding behaviour with resulting distortions in the allocation of capacity. Transco supported this view (Ofgem, 2001), and concluded that it was unconvinced that long-term auctions would result in the provision of capacity at lowest cost. Transco also argued there was only limited competition among shippers, and this could result in bids not revealing the true valuations that shippers placed on capacity. 
Ofgem generally has not accepted these arguments. With respect to the rebate mechanism, whereby some of the revenues obtained in the auctions may be rebated to organizations which are themselves bidding, Ofgem acknowledges that a distortion in bidding behaviour might arise. Ofgem also argues, however, that, for a major player, the effect could operate in either direction. Thus while a bidder may overbid because he anticipates that a refund will reduce the net cost of the bid to him, a bidder which has a large market share may also attempt to exert its power by attempting to drive down capacity prices.

Ofgem also argues that it is only when large variations from Transco's target revenues can be predicted with reasonable accuracy that distortions to bidding behaviour can emerge. Given that bidders are uncertain about the extent of any over-recovery in revenues by Transco from the auction, then the higher the bid which any one shipper makes, the greater is the overall cost which that shipper bears in relation to others. If their bid is relatively high the rebate they receive may not compensate them.

Because of these uncertainties and their effects, Ofgem believes that shippers will have an incentive to ensure that bids closely reflect the value of the capacity to them. In support of this view, Ofgem produced evidence from the experience of the short-term auctions that there was no clear relationship between a shipper's market share and the bids made.

Gas producers are keenly interested in the terms of access to the NTS. (Some, but not all, producers are also shippers). From their viewpoint it is important not only that the costs of access are as low as possible, but that capacity is available under stable, transparent, and predictable terms. Increasingly the new gas fields in the UKCS are quite small. Problems of obtaining access to the infrastructure and the terms of such access can have a major effect on the economic viability of such fields.

Experience to date with short-term capacity entry auctions has hardly been reassuring. The prices can be claimed to be volatile and relatively high. Extraordinarily high prices have been paid at St Fergus (up to 12 pence per therm). The shortage of capacity at that terminal has been known for several years, but producers and shippers could legitimately claim that the response to date in terms of new investment has been very slow. Producers desire guaranteed capacity availability to reduce the risks relating to their investments. They would be able to purchase NTS capacity rights only in the secondary market. With respect to over-recovery of revenues from auctions by Transco, the rebate system currently employed distributes the excess in relation to the commodity (not capacity) charges under Transco's price formula. This favours shippers who move gas from the national balancing point. Arguably, this discriminates against those who directly incurred the original capacity charges.

There are, of course, other methods of allocating capacity. One is based on historic throughput using regulated prices. A provision of this scheme would withhold some capacity for new entrants. Ofgem does not support this mechanism on the grounds that it would favour existing major players and confer windfall gains on them when trading took place on the secondary market. Reserving some capacity for new entrants would run contrary to Transco's obligation to offer capacity in a non-discriminatory fashion.

The suggestion that capacity be allocated on a volume auction basis was also not favoured by Ofgem. Its concern was that this could lead to distortions. Shippers would have an incentive to bid for large volumes. Bids would have to be scaled down to ration the available capacity in the likely situation where the full market price exceeded the administered price. Some shippers who received allocations in excess of their own needs could then sell the rights on the secondary market at a profit. Ofgem also express concern that the use of volume auctions would mean that the true value of capacity to the users was not revealed.

Another possible allocation mechanism is through bilateral contracts, whereby capacity prices would be agreed between Transco and shippers. Ofgem is concerned that such a scheme would lack transparency, and might be discriminatory and not encourage competition. Ofgem fears that this type of scheme with tailored terms for each contract would inhibit secondary trading and lock in capacity to an undesirable degree. The extent of these possible problems is open to debate. In some markets indi- 
vidual contracts are certainly compatible with effective competition.

Ofgem (2001) expressed surprise at the suggestion that shippers might be unwilling to commit to longterm purchases of capacity. The regulator feels that under a well-designed auction system shippers would be able to purchase capacity for a range of contract periods either in the primary auction markets or in the secondary markets. Ofgem believes that shippers affiliated to producers can obtain long-term contracts which should ensure that gas can be produced and landed without undue risks relating to the field investment. It is also argued that shippers who have long-term contracts with large customers, such as power generators, can effectively hedge their risks.

There are differing views on this issue. For effective hedging, well-functioning futures markets are required. Gas futures markets have developed over the past decade. To date, however, there is a lack of liquidity in the long-term market, which is the relevant one in the present context. Whether effective hedging can be obtained on the necessary scale is thus debatable.

What difference does this make to the ability of shippers to sign long-term contracts? It is arguable that fully functioning futures markets are clearly desirable but perhaps not essential. In some cases, for example the recent agreement between BP and Statoil, the parties in question can bear the risks because of the size of their equity in relation to the size of the contract. Where this circumstance does not prevail shippers will be more exposed. The position in the gas market itself is clearly of major importance. To limit the shipper's risk exposure it is essential that the gas price indexation in the sales contract reflect the market risks in question.

In general it can be argued that in the UK, where Transco is quite independent from the gas market itself and has an obligation to provide infrastructure on a common-carriage basis, the risks on gasmarket participants are thereby reduced, compared to the typical situation on the Continent, where the infrastructure provider is also a major participant in the gas market itself. Further, on the Continent the infrastructure provision is typically on an openaccess basis rather than common carriage. This also means that the risks facing gas-market participants are greater because access may not be guaranteed. In some countries the tariffs are also negotiable rather than determined by regulation.

A concern in the UK clearly relates to the volatility of capacity entry auction prices which has been a feature of at least some elements of the short-term market to date. Both producers and shippers desire a more stable market situation. To what extent this can be expected when experience with long-term auctions has been obtained, remains an open question.

A further concern in the UK is whether in practice Transco will respond in an expeditious manner to meet the needs of the growing and changing gas market. A related issue is the interpretation of the requirement to develop and maintain an economical and efficient infrastructure. It is certainly arguable that the definition expressed in terms of 1 in 20 peak days is now outmoded. The whole gas market has changed dramatically since this requirement was established. Not only has there been market liberalization, but the importance of the seasonality in demand has been considerably reduced. The increased use of gas in industry and for power generation, plus, in more recent times, exports through the Interconnector, are responsible for this development. The overall growth in demand and the distribution of requirements at the different terminals has clearly not been fully anticipated. It is also generally agreed that future market uncertainties remain high. (It should be noted here that Transco's allowed capital expenditure has to be approved by Ofgem and generally Transco has wished to spend more than Ofgem desires. Thus for the next review (2002/3-2006/7) Transco wishes to invest $£ 2.4$ billion while Ofgem currently feels $£ 1.9$ billion is appropriate.)

In these circumstances it is arguable that a prudent interpretation of the obligation to provide an economical and efficient infrastructure should incorporate a safety margin to reflect these uncertainties. A modest element of excess capacity is likely to be very inexpensive from a national viewpoint compared to the costs caused by shortages of capacity. For example, for a typical annual domestic gas bill of $£ 300$ the NTS component is less than 4 per cent. The cost of every extra $£ 100 \mathrm{~m}$ investment ex- 
pressed in terms of the additional cost per domestic consumer is below 50 pence per year. This puts into perspective the costly effects of the shortage of capacity such as has occurred at St Fergus in recent years.

Use of long-term capacity auctions to provide investment signals to Transco needs to be supplemented by other incentives, including penalties for failing to provide the capacity. Recent experience indicates legitimate concern about whether the capacity will be provided at the required time. Looking ahead, with the prospective increase in demand, and given that long-term capacity auctions have not yet started nor the detailed rules been finalized, doubts remain about whether all the required capacity will be available at the right time and place.

On the Continent, where liberalization and competition have not proceeded as far as in the UK, the problems of provision of infrastructure will also have to be faced, given the expected growth in demand and the concern about security of supply. Surprisingly, the European Commission(EC, 2000), while acknowledging the need for infrastructure expansion, does not discuss in detail the issues noted above. As noted above, the current institutional structures and regulatory arrangements are generally different from the UK, with open access, often on a negotiated rather than regulated basis, being prevalent rather than common carriage. More fundamentally, transportation and trading functions are often still combined. It can be argued that these features will not be permanent because of their inherent problems. It is quite possible that major changes will be made to the regulatory framework, incorporating many of the lessons from the UK experience. In the meantime the uncertainties leave an unsatisfactory investment environment.

Many of the issues which have been the subject of debate in the UK are likely to become live issues on the Continent over the next few years. For example, in the Netherlands there are disputes between Gasunie and the regulator on the question of whether tariffs should be cost-based or not, and whether tariffs charged should be published. Gasunie has also recently announced that it will separate its trading and transportation activities, though it has no legal obligation to do so, because it believes this is in line with evolving trends. In general, continued integration of the two functions is not only likely to inhibit the evolution of competition, but, where it is combined with a system of open access (rather than common carriage), it can inhibit the optimal growth of infrastructure capacity. The infrastructure owner may be reluctant to build more capacity when the prime beneficiary is a competitor to his own trading business.

\section{GAS CONTRACTS}

Gas contracts may be made more efficient by the presence of an adequate infrastructure. The changing market structure in Europe along with rising demand and the need for increased imports also have major implications for the sources of supply and the associated contracts.

In the UK major changes occurred to gas contracts between producers and purchasers some years ago. The traditional field depletion-based contracts with a very high take-or-pay element have been modified. Typically, there are volume contracts with somewhat reduced take-or-pay-elements. Indexation is likely to be related to an inflation factor and the prices of competing fuels. The spot gas price may also be one of the elements in the indexation, reflecting the opportunities of buyers to purchase in the spot markets.

On the Continent, the typical long-term contracts for supplies from Norway, Russia, and Algeria tend to be specified in terms of volumes with a very large take-or-pay element. The indexation is primarily to oil product prices. In recent years the weighting in favour of gas oil has increased compared to fuel oil, reflecting the reduced consumption of the latter. In some countries indexation is also linked to a main competing fuel.

How efficiently gas will be supplied to Europe in the future depends in part on the design of the appropriate contracts between producers and buyers. These have also to be seen in the context not only of the evolving liberalization and competition requirements but also of the conditions prevalent in the centres of production.

On the basis of the known reserves and likely future discoveries it is clear that Norway and Russia will be 
major sources for many years. In Norway proven reserves are officially stated at 44 trillion cubic feet. Wood Mackenzie (2001) estimates that between now and 2012 new 'probable' fields containing recoverable reserves of 31 trillion cubic feet could be developed. A very high proportion of this gas is located in mid-Norway and the Barents Sea, where investment costs, including the provision of new offshore infrastructure, will be required. In the Barents Sea, liquefied natural Gas (LNG) is currently viewed as the most likely development concept.

Recently there has been a major change in the contractual situation regarding Norwegian gas exports. Under pressure from the EU, the arrangement whereby all export contracts were negotiated by one single group, led by Statoil and Norsk Hydro, and commonly known as the GFU, has been abolished. The EU has also instigated legal proceedings against Statoil and Norsk Hydro with the objective of requiring them to renegotiate the existing contracts. Whether this will happen and whether a more competitive export market will develop is still unclear. Statoil and Norsk Hydro are expected to challenge the EU Commission and to argue that the GFU scheme was imposed upon them by the Norwegian government. It is noteworthy that Statoil will also market the state's direct share of gas (now called Petoro). According to Schroder Salomon Smith Barney (2001) this combination amounts to nearly 60 per cent of Norway's proven gas reserves.

It is also noteworthy that the combined shares of Statoil and Petoro in the giant Troll field amount to 55 per cent of the total. There is much uncontracted gas in this field, and to what extent other partners will enter into independent export contracts is unclear. A further relevant feature is the interventionist practice of the Norwegian government with respect to field development, depletion, and exports. The ability to approve developments and contracts could also inhibit the emergence of competition among producers.

In Russia proven reserves are estimated at over 48 trillion cubic feet. While well over 80 per cent of Russia's current gas production comes from western Siberia, incremental supplies will increasingly have to come from higher-cost and remote areas such as Yamal. The Russian gas industry is also faced with the prospect of major structural change which adds a complicating factor from the viewpoint of contracts with western Europe. Gazprom, a vertically integrated company, currently has a near monopoly of the industry, especially in transportation, and supply (including exports). In 2001 the government announced a proposal to deregulate the industry. The proposals involve the separation of Gazprom's transportation assets from those of production and supply, followed by separate accounting and the spinning off of Gazprom's pipeline business. Transparent tariffs would be established involving non-discriminatory access by third parties. At the production stage several subsidiaries of Gazprom would be established with separate accounting. Subsequently they would compete with each other and with independent producers. As far as exports to non-former-Soviet-Union (FSU) countries are concerned, for the foreseeable future Gazprom would probably retain a monopoly though there is a possibility of other companies becoming exporters in the longer term.

These are far reaching proposals which would have major implications for all connected with the industry including customers in western Europe. Currently Gazprom not only has a near monopoly of the industry, but the pricing structure in the gas chain is far removed from the structure of the related costs. United Financial Group (2001) estimates that, under the transfer pricing system employed by Gazprom, the transfer price between the production and transmission parts of the business is set artificially low. Thus 90 per cent of the company's total costs are allocated to transmission and only 10 per cent to the rest of the business. With a more accurate cost allocation the split would be around 75:25 per cent.

Whether these recent proposals will be implemented is a moot point. The fact that the proposals have been made by itself introduces some uncertainty. They come on top of a situation where Gazprom's total production has been falling (although its exports to non-FSU countries have continued to grow), and where concern has been expressed about the condition of the transportation infrastructure.

From the viewpoint ofEuropean countries importing increasingly large quantities of gas, the developments in both Norway and Russia noted above are 
of much interest. To what extent there will be competition among important producers can clearly affect the market price.

Other contractual issues are important in the supply of gas from producing to consuming countries. In the medium-term future the economic environment within which agreements are required will be significantly different from that which has been typical in the past. The new fields in both countries will be more remote and generally costlier to develop, and there may be more competition at both the production stage and in the end markets for the gas. Producers like long-term take-or-pay contracts to reduce their investment risks. Purchasers have been willing to sign these because their market risks have been limited by entrenched near-monopoly rights. These are now clearly being eroded, though the pace of change still remains uncertain.

The future market situation clearly involves more risks. Producers will be keen to preserve substantial take-or-pay elements in their contracts. Purchasers may be more reluctant. The experience of British Gas in the 1990s, when it found itself with substantial 'excess' gas in its contracts with producers, will be remembered. The main established wholesalers, such as Gasunie, have already experienced large falls in their market shares.

As was noted above, currently there is still insufficient liquidity to enable effective hedging for large long-term contracts to take place on the necessary scale. Futures markets are, of course, likely to grow as the demand for the facility increases. It is likely, however, that contracts will have to become more flexible in their structure to deal with the changing market situation. From the producer's viewpoint it is essential that a market price be clearly obtainable. In a liberalized market there should be more gas-togas competition. In the European context it is the likely extent of this which is currently unclear. Longterm contracts can accommodate this uncertainty by the inclusion of price reopener/review clauses. These are, in fact, already common to a limited extent in existing contracts, with 3 -year intervals between reviews being the norm. It is also understood that at least some recent contracts acknowledge the development of gas-to-gas competition by the inclusion of the spot gas price as one (small) element in the indexation formula. From this basis it is possible to see a basis for long-term agreements which could accommodate major changes in the gas market structure. This has, of course, already happened in the UK, but, arguably, the risks and likely field investment costs in the countries which are likely to be supplying large volumes of gas to western Europe will be considerably greater.

Over the longer term there are many other possible sources of incremental gas for western Europe apart from Norway and Russia. The European Commission (EC, 2000) identified Algeria, Iran, Qatar, Nigeria, and Turkmenistan. These countries all have very large reserves by world standards. Given the distances, the delivered costs are likely to be significantly higher than current levels. It is noteworthy, however, that there have been substantial reductions in the costs of developing and transporting gas in the form of LNG in recent years. Further progress is confidently expected over the next decade. Historically, LNG contracts have had very substantial take-or-pay elements, and those to Europe have had indexation clauses heavily related to oil prices. Some adaptation to the probable new market situation is likely to be needed.

\section{CONCLUSIONS}

Gas demand throughout western Europe is very likely to grow substantially over the next two decades. This will have several consequences, particularly $(a)$ a growing need for imports, which will become very substantial even by 2010 , and $(b)$ a need to expand the infrastructure network. The need for substantial imports in the medium term applies to the UK, where production is likely to peak within a few years and then decline at quite a fast pace.

The required expansion in the infrastructure will take place in the context of increasing liberalization in the gas market. The main infrastructure providers are all faced with heavy and changing regulation. The challenge for them and the regulators is to ensure that adequate capacity is provided at the right time and in the right place. Across Europe there is a variety of regulatory and incentive arrangements. In the UK, where there is a full common-carriage obligation, the new system of providing incentives to the infrastructure provider is through the auction of capacity rights to shippers. How 
efficiently this system will function compared to other schemes, such as bilateral contracts between user and provider, or the judgement of the provider and regulator, is still unclear.

In the UK there is at least a settled basic industry structure of complete separation of infrastructure provider on a common-carriage basis from the activities of gas production and supply. The problem for the provider is to deal with a liberalized market subject to considerable uncertainties at both the gas production and final market stages. A further complication concerns the uncertainties relating to the gas import landing points.

On the Continent the basic industry structures have generally not yet been settled. Infrastructure provision and gas supply are still widely undertaken by the same organization. Open access is common but transparency and certainty for third-party users is often arguably inadequate. The structures as well as the regulatory arrangements are both subject to further change, but the pace and extent are still uncertain. The infrastructure providers thus have neither a settled industry structure nor settled investment incentive scheme facing them. There is a clear benefit to all parties in the expeditious development of a settled industry structure and regulatory framework. The experience of the UK indicates that continuous regulatory uncertainty and changes increases the cost of capital to the infrastructure provider, to the disadvantage of all parties. Shortage of capacity will impose large costs to the overall economy and a margin of excess capacity may be regarded as a relatively cheap insurance policy.

An efficiently provided infrastructure can help to facilitate long-term contracts between producer and gas purchasers. This market is also changing significantly. There are regulatory changes affecting Norway and Russia which may increase the level of competition among producers. The uncertainties regarding the pace and extent of (downstream) market liberalization may make the conclusion of long-term contracts more difficult, especially when high-cost and very distant gas sources will be involved. The extent to which recent contracts have already incorporated some market liberalization in key clauses gives some confidence that future ones can accommodate a much more liberal market structure.

\section{REFERENCES}

EC (2000), Towards a European Strategy for the Security of Energy Supply, COM (2000) 769, Brussels, Commission of the European Communities, Annex, Technical Document.

DTI (2001a), Development of UK Oil and Gas Resources, London, Department of Trade and Industry.

- (2001b), Energy Projections for the UK, Energy Paper No. 68, London, Department of Trade and Industry.

Energy Contract Company (2001), UK Gas Market Review, 2001, Twickenham.

IEA (2000), World Energy Outlook 2000, Paris, International Energy Agency.

Ofgem (2000a), Long Term Signals and Incentives for Investment in Transmission Capacity on Transco's National Transmission System: A Consultation Document, London, Office of Gas and Electricity Markets, May.

- (2000b), Long Term Signals and Incentives for Investment in Transmission Capacity on Transco's National Transmission System: Conclusions on the Framework, London, Office of Gas and Electricity Markets, December.

- (2001), Long Term Signals and Incentives for Investment in Transmission Capacity on Transco's National Transmission System: The New Regime, London, Office of Gas and Electricity Markets, March.

Schroder Salomon Smith Barney (2001), Equity Research: Norway, London, August.

Transco (2000), Transportation Ten-Year Statement 2000, Solihull.

(2001a), Transporting Britain's Energy: Consulting on Customer Requirements from Transco's Network, Solihull, May.

- (2001b), Transporting Britain's Energy: Conclusions of Transco's Consultation for Future Network Requirements, Solihull, July.

United Financial Group (2001), Gazprom: Brave New World, Moscow, August.

Wood MacKenzie (2001), North West Europe Upstream Report, No. 180, Edinburgh, July. 